\title{
The performance of laboratory tests in the management of a large outbreak of orally transmitted Chagas disease
}

\author{
Belkisyolé Alarcón de Noya ${ }^{1,2} /{ }^{+}$, Zoraida Díaz-Bello ${ }^{1}$, Cecilia Colmenares ${ }^{1,2}$, \\ Reinaldo Zavala-Jaspe ${ }^{1}$, Teresa Abate ${ }^{3}$, Rosa Contreras ${ }^{2}$, Sandra Losada ${ }^{4}$, \\ Domingo Artigas $^{5+}$, Luciano Mauriello', Raiza Ruiz-Guevara ${ }^{2}$, Oscar Noya ${ }^{2,4,5}$
}

\begin{abstract}
${ }^{1}$ Sección de Inmunología ${ }^{2}$ Cátedra de Parasitología ${ }^{3}$ Sección de Biología Molecular ${ }^{4}$ Sección de Biohelmintiasis, Instituto de Medicina Tropical, Escuela de Medicina Luís Razetti, Universidad Central de Venezuela, Caracas, Venezuela ${ }^{5}$ Centro para Estudios sobre Malaria, Instituto de Altos Estudios Dr Arnoldo Gabaldón, Instituto Nacional de Higiene Rafael Rangel, Ministerio del Poder Popular para la Salud, Caracas, Venezuela
\end{abstract}

Orally transmitted Chagas disease (ChD), which is a well-known entity in the Brazilian Amazon Region, was first documented in Venezuela in December 2007, when 103 people attending an urban public school in Caracas became infected by ingesting juice that was contaminated with Trypanosoma cruzi. The infection occurred 45-50 days prior to the initiation of the sampling performed in the current study. Parasitological methods were used to diagnose the first nine symptomatic patients; T. cruzi was found in all of them. However, because this outbreak was managed as a sudden emergency during Christmas time, we needed to rapidly evaluate 1,000 people at risk, so we decided to use conventional serology to detect specific IgM and IgG antibodies via ELISA as well as indirect haemagglutination, which produced positive test results for $9.1 \%, 11.9 \%$ and $9.9 \%$ of the individuals tested, respectively. In other more restricted patient groups, polymerase chain reaction (PCR) provided more sensitive results ( $80.4 \%)$ than blood cultures (16.2\%) and animal inoculations (11.6\%). Although the classical diagnosis of acute ChD is mainly based on parasitological findings, highly sensitive and specific serological techniques can provide rapid results during large and severe outbreaks, as described herein. The use of these serological techniques allows prompt treatment of all individuals suspected of being infected, resulting in reduced rates of morbidity and mortality.

Key words: Chagas disease - oral transmission - outbreak - diagnosis - serology - Venezuela

In Venezuela, effective control measures successfully reduced the annual incidence of Trypanosoma cruzi infections from 10/1,000 individuals in the 1950s to $1 / 1,000$ in the 1980 s (Feliciangeli et al. 2003). Since then, the recorded outbreaks of acute Chagas disease (ChD) have been as follows: between 1988-1996, 59 cases occurred in the western states of Venezuela (Añez et al. 1999), after which nine cases involving two deaths occurred during the period of January 2006-March 2007 in the same endemic area (Añez et al. 2007). In 2004 and 2006, the deaths of two children near Caracas were documented (Alarcón de Noya et al. 2009). Nevertheless, an outbreak of orally transmitted $\mathrm{ChD}(\mathrm{OChD})$ in a school in a middle class neighbourhood in Caracas was the warning signal that $\mathrm{ChD}$ was re-emerging via a different mode of transmission, i.e., the oral route (Alarcón de Noya et al. 2010b). Although this form of the disease

Financial support: Immunology Section/Tropical Medicine Institute/ $\mathrm{UCV}$

† In memoriam

+ Corresponding author: belkisyole@yahoo.com.mx

Received 26 February 2012

Accepted 11 July 2012 is well known elsewhere, it is not commonly observed in Venezuela; however, five additional oral outbreaks have occurred since the outbreak in the school in different parts of the country (Alarcón de Noya et al. 2010a, ProMED 2012). In Brazil, several episodes of oral transmission have been reported since 1968 (Valente et al. 2008) and 776 cases that occurred from 2000-2010 have been attributed to foodborne transmission (ShikanaiYasuda \& Barbosa Carvalho 2012). Argentina, Ecuador, Colombia (Alarcón de Noya et al. 2010a) and Bolivia (Santalla Vargas et al. 2011) have also documented cases of OChD. A laboratory diagnosis of $\mathrm{ChD}$ depends on the type of clinical or epidemiological conditions involved, as infection and diagnosis may take place in patients who come into direct contact with the vector, but diagnosis can also occur under special circumstances, such as through blood screening in blood banks, cardiology and obstetric consultations, transplantation units or, less frequently, during large outbreaks of $\mathrm{OChD}$, all of which must be managed as real clinical emergencies. For example, in Venezuela, during December 2007 (Alarcón de Noya et al. 2010b), an outbreak occurred in an urban school that was presumably linked to the ingestion of contaminated home-made juice that had been prepared in a different part of the city where triatomines were present.

The aim of this study is to provide information about the parasitological, immunological and molecular laboratory tests used in diagnosing $\mathrm{ChD}$ to gleam further knowledge from the largest $\mathrm{OChD}$ outbreak ever reported. 


\section{SUBJECTS, MATERIALS AND METHODS}

Study population - The study population consisted of students, teachers and administrative personnel from a school located in the municipality of Chacao in Caracas, Venezuela. Once the primary case was diagnosed (Martín et al. 2009) and the epidemiological link to another case was established (Alarcón de Noya et al. 2010c), parasitological examinations and serological tests were carried out in these cases, in addition to other symptomatic patients who voluntarily requested medical attention at the Tropical Medicine Institute (IMT), Universidad Central de Venezuela in Caracas. After the death of a five-year-old student, most of the school community was managed as part of an on-site emergency, both in the school and at the hospital, where several of the patients were hospitalised. T. cruzi infection was diagnosed by collecting only one tube of blood for serological testing, except for in people who were symptomatic at the time of the interview and from whom additional blood was taken for parasitological or molecular testing (Supplementary data). For logistical and ethical reasons, a unique protocol could not be followed and, consequently, the results are simply presented as they were obtained over time. It was not possible to re-sample the blood of individuals with positive serological tests to isolate the parasite before treatment because the treatment had to begin before the group dispersed for the Christmas holiday.

Direct parasitological tests - Observations of the parasite were performed using fresh blood smears as well as Giemsa-stained preparations (WHO 2002). Three-four thick slides per person were used for the Giemsa procedure.

Cultures - Aliquots of $2 \mathrm{~mL}$ of blood samples collected by venipuncture in sodium citrate tubes were added to bacto agar blood base (BAB) culture medium and observed every 10 days for epimastigotes. Once the cultures were found to be positive for epimastigotes, they were transferred to liver infusion tryptose medium with 10\% foetal bovine serum (Mourão \& Mello 1975).

Animal inoculations - Two one-week-old mice were inoculated with total blood intraperitoneally (0.3$0.5 \mathrm{~mL}$ ) (Luquetti \& Rassi 2000). In some cases, when direct microscopic examination showed that a sample was positive for the parasite, but the patient's blood culture and inoculated mice were negative after a month, the animals were sacrificed and their heart blood was cultured again in new BAB medium (sub-cultures).

Immunodiagnosis - In all of the applied diagnostic techniques, a delipidised antigen specific for epimastigotes was used. This antigen was validated under a national initiative by the Minister of Health (González et al. 2005) and has been used in our laboratory for five decades. Quality control was performed to confirm the reactivity among different lots of antigen.

Immunoenzymatic assay - An in-house immunoenzymatic assay (ELISA) (Voller et al. 1976) was performed with the delipidised antigen specific for $T$. cruzi epimastigotes and processed using Maxisorp plates, as described by Maekelt (1960) and Díaz-Bello et al. (2008). ELISAs involving anti-human $\operatorname{IgM}$ and $\operatorname{IgG}$ alkaline phosphatase conjugates (Sigma Chemical Company, St. Louis, MO, USA) were carried out simultaneously in all sera from individuals at risk.

Indirect haemagglutination (IHA) - Previously described methods were used in the IHA procedure (Jacobs \& Lunde 1957), in which the delipidised epimastigote antigen was adsorbed by fresh sheep red cells. The IHA procedure was carried out for all individuals as a confirmatory second test.

Western blotting (WB) - In people showing only one positive result, WB was performed using lysates of the T. cruzi epimastigote antigen according to the technique described by Laemmli (1970), as modified by Noya et al. (1995) and adapted for ChD diagnosis in our laboratory by Zavala-Jaspe et al. (2005). Serum detection of five or more specific molecules of the epimastigote antigen was considered a positive result.

Polymerase chain reaction (PCR) - To preserve DNA, $5 \mathrm{~mL}$ of blood was mixed with an equal volume of $6 \mathrm{M}$ guanidine $\mathrm{HCl} / 0.2 \mathrm{M}$ EDTA and processed based on previous methods described by Schijman et al. (2003). The PCR amplifications targeted a 330-bp fragment of $T$. cruzi kinetoplastid minicircle DNA (Sturm et al. 1989).

Case definition - A confirmed case of $\mathrm{ChD}$ is any individual with parasites in their peripheral blood and all individuals with at least two positive serologic tests based on different methods (WHO 2002). Consequently, in this study, the considered oral transmission cases include all individuals from the school, either with or without parasitaemia, showing positive results in ELISA (IgG/IgM) and at least one other positive confirmatory test (IHA or WB) who had not been subjected to previous ChD transmission (WHO 2002, OPS/OMS 2006). Patients were considered as severely ill if they had a long-lasting high fever, facial or generalised oedema, prostration and any cardiac complications. The mildly symptomatic group consisted of patients with a low fever, headache, anorexia or decay.

Ethics - All of the parents/guardians of the participating minors and all of the participating adults signed an informed consent form that was reviewed and approved by the Ethical Scientific Committee of the IMT. We held meetings and informational assemblies with the parents/ guardians in the school in the presence of local authorities and members of the Ethical Scientific Committee.

\section{RESULTS}

The study population was comprised of 747 students, 237 school personnel (or people who had visited the school frequently) and 16 individuals who were related to the family who had prepared the beverages (Alarcón de Noya et al. 2010b).

Table I shows the results of the laboratory diagnostic tests from the initial group of severely ill subjects who participated in parasitological testing. T. cruzi was detected in all of the subjects by different means. Eight of 
the nine patients examined showed positive blood smears (either fresh or stained smears) as well as positive cultures or inoculated animals that tested positive. The one exception was patient number 8 , for whom parasites were not detected by direct examination or in his blood culture, but when the blood from the inoculated mice was subcultured, parasites were recovered. The samples from patients 7 and 9 were subjected to the same procedures described above, although their blood cultures were also positive. All of the parasitological results (parasite visualisation in fresh blood smears, cultures and inoculation of animals) corresponded with each other for only four out of the nine subjects.

During a field study, additional laboratory tests were performed in 34 mildly symptomatic people (34 fresh smears, 132 Giemsa stains, 68 inoculated mice and 34 blood cultures). All of these individuals were $\mathrm{OChD}$ cases who were negative for parasites, with the exception of four positive Giemsa smears (Supplementary data).

The general sensitivity of parasitological diagnosis via fresh blood smears and patient blood cultures was approximately the same: seven/43 (16.2\%), six/43 $(13.9 \%)$ for Giemsa-stained smears and five/43 (11.6\%) for inoculated mice.

Conventional serology testing was based on results of the ELISA (IgM/IgG) and IHA tests. (Table II). A total of 119 people tested positive for $\operatorname{IgG}$ and of these patients, 103 presented another positive serologic test $(99$ showed a positive IHA result and 4 a positive WB result) and were considered as confirmed cases of $\mathrm{ChD}$. The majority $(74.7 \%)$ of the confirmed cases were younger than 20 years of age ( 77 students). Sixteen subjects (8-42 years of age) were IgG positive, one was IgM positive and all of the subjects were IHA negative (Table III). When WB was performed in the samples from this group, their sera did not recognise specific molecules of the $T$. cruzi antigen, but based on the epidemiological link, the group received anti-parasitic treatment and continues to receive clinical and laboratory follow-up testing. Consequently, to estimate the prevalence of acute cases, we considered 103 of the 1,000 subjects examined $(10.3 \%)$. None of these individuals were concurrently positive for IgM and negative for IgG. The IHA test was positive in $96.1 \%$ of the oral cases, appearing to be less sensitive than the IgG immunoenzymatic assay, which detected $100 \%$ of the oral cases. Again, there were no cases showing a positive IHA test and a negative IgG test.

Finally, a random selection of 150 out of 991 subjects was investigated to detect parasitic DNA (Supplementary data). Forty-four subjects showed positive serological tests, while the PCR assay detected T. cruzi kinetoplastid DNA in 30 children and five adults ( $79.54 \%$ sensitivity). The remaining 106 subjects presented PCR results that were negative for parasitic DNA and negative serological tests (100\% specificity). The PCR test was also positive in six out of the seven severely symptomatic individuals (Table I). The global sensitivity of the PCR testing was $80.4 \%$ (41 PCR-positive/51 serologically positive patients).

\section{DISCUSSION}

Classical guidelines have been described for the routine diagnosis of the acute and chronic phases of $\mathrm{ChD}$ (WHO 2002, 2007) and for sporadic cases (Añez et al. 1999, Morocoima et al. 2008). However, sudden and unexpected outbreaks of OChD have to be managed as medical emergencies. During a 16-month period in Venezuela, massive outbreaks of $\mathrm{OChD}$ occurred in two schools, one in an urban setting and the other in a rural setting (Alarcón de Noya \& Martínez 2009, Alarcón de Noya et al. 2010b).

TABLE I

Acute Chagas disease screening in severe ill patients of the oral outbreak, Caracas, Venezuela, 2007

\begin{tabular}{|c|c|c|c|c|c|c|c|c|c|c|c|c|c|c|}
\hline \multirow[b]{4}{*}{ Patient } & \multirow[b]{4}{*}{ Age } & \multicolumn{13}{|c|}{ Diagnostic methods } \\
\hline & & \multicolumn{9}{|c|}{ Parasitologic } & \multicolumn{3}{|c|}{ Serologic } & \multirow{3}{*}{$\begin{array}{c}\text { Molecular } \\
\text { PCR }\end{array}$} \\
\hline & & \multicolumn{2}{|c|}{ Blood smears } & \multicolumn{4}{|c|}{$\begin{array}{c}\text { Mice } \\
\text { (days of evolution) }\end{array}$} & & \multicolumn{2}{|c|}{ Blood culture } & \multirow{2}{*}{$\begin{array}{l}\text { ELISA } \\
\text { IgM }\end{array}$} & \multirow{2}{*}{$\begin{array}{l}\text { ELISA } \\
\operatorname{IgG}\end{array}$} & \multirow[b]{2}{*}{ IHA } & \\
\hline & & Fresh & Giemsa & 10 & 20 & 27 & 36 & 50 & Mice $^{a}$ & Human & & & & \\
\hline 1 & 9 & + & + & - & + & - & + & + & ND & + & + & + & 1.024 & + \\
\hline 2 & 55 & + & - & - & + & + & + & + & ND & + & + & + & 256 & + \\
\hline 3 & 49 & + & - & - & - & - & - & - & ND & + & + & + & 256 & - \\
\hline 4 & 34 & + & - & - & + & + & + & + & ND & + & + & + & 4.096 & ND \\
\hline 5 & 55 & + & - & - & + & + & + & + & ND & + & + & + & 64 & ND \\
\hline 6 & 23 & - & + & - & - & - & + & - & - & - & + & + & 4.096 & + \\
\hline 7 & 49 & + & - & - & - & - & - & - & + & + & + & + & 64 & + \\
\hline 8 & 44 & - & - & - & - & - & - & - & + & - & + & + & 256 & + \\
\hline 9 & 55 & + & - & - & - & - & - & - & + & + & + & + & 256 & + \\
\hline
\end{tabular}

a: sub-cultures; Ig: immunoglobulin; IHA: indirect haemagglutination; ND: not done; PCR: polymerase chain reaction. 
The present study, as an example of an urban $\mathrm{ChD}$ outbreak, allows comparison of each diagnostic method used under the conditions described herein. Isolation of the parasite is usually easy in the acute phase of the illness. For example, nine parasite isolates were obtained from the severely ill groups of patients prior to treatment. During a suspicious ChD outbreak, health authorities require isolation of parasites to verify the aetiology of the infection. A complete parasitological and immunological evaluation was performed in the initial group of patients, confirming the aetiology of the outbreak in an area that is non-endemic for ChD. Thereafter, only conventional serology methods, including ELISA (IgM/ $\mathrm{IgG}$ ) and IHA, were applied in all individuals at risk. This choice was based on the urgent need for rapid diagnosis and treatment within a four-day-period prior to Christmas vacation. The use of fresh blood smears, Giemsa stains and PCR assays was restricted to a very limited number of cases because these techniques are considered cumbersome and time consuming in an urgent situation. Because this investigation occurred in an elementary school, in a population represented mostly by children, the minimum volume of blood required to perform diagnostic screening was collected.

Examination of fresh blood smears and stained smears is usually performed by routine clinical laboratories. These techniques detected only seven and two cases, respectively, in the severely symptomatic group of patients. The parasitological outcomes were different between the severely ill group and the subset of mildly symptomatic people in the field study. The parasitaemia was likely lower in the second group, or the antibiotics may have inhibited the parasite's growth, because all people in this group presented a misleading diagnosis. Other parasitological assays, such as the capillary test (Strout 1962), animal inoculations, in vitro cultures and the time-consuming xenodiagnostic test (Luquetti \& Rassi 2000), should be utilised in reference diagnostic centres when possible. Direct microscopic examination of fresh specimens allows rapid visualisation of motile T. cruzi parasites and provides an immediate idea of the level of parasitaemia. A high level of parasitaemia is only present in acute cases and may be the first signal of a microepidemic. In severely symptomatic patients, fresh blood smears were more sensitive for detecting parasites than Giemsa-stained smears, suggesting that the former technique should be routinely applied in people with a long-lasting fever from an unknown cause. When T. cru$z i$ trypomastigotes are detected in peripheral blood by any technique during an outbreak, it is necessary for the clinicians and personnel involved in control programs to act rapidly and contact all of the individuals at risk of infection to prevent morbidity and mortality. Parasite isolates can only be obtained through in vitro culturing or animal inoculation, both of which are more sensitive during the acute phase. Nevertheless, these two procedures must be performed at a reference centre before anti-parasite treatment can be initiated.

The importance of screening for specific $\operatorname{IgM}$ and IgG antibodies by ELISA was demonstrated by the fact that these tests can confirm the acute condition of the infection. The detection of IgM was very specific in the present study, as there were no false positives detected compared to the results of the ELISA IgG test. Based on findings of the epidemiological investigation, it was estimated that we intervened at the school six weeks after exposure to the alleged inoculum, when IgG antibodies were expected to be present in all subjects. At this time, the IgM titres had diminished in $12.6 \%$ of the subjects. This result was predictable, considering the kinetics of these antibodies during the acute phase of the infection (Janeway et al. 2001). The rapid application of the ELISA technique for simultaneously detecting IgM and IgG allowed prompt diagnosis and administration of treatment and thus, occurrences of morbidity and mortality were reduced. When large acute outbreaks of OChD are suspected, conventional serological tests, which are available in basic clinical laboratories, can detect specific

\section{TABLE II}

Conventional serology for the diagnosis of Trypanosoma cruzi infection applied to all persons under risk during the outbreak of oral transmission, Caracas, Venezuela 2007

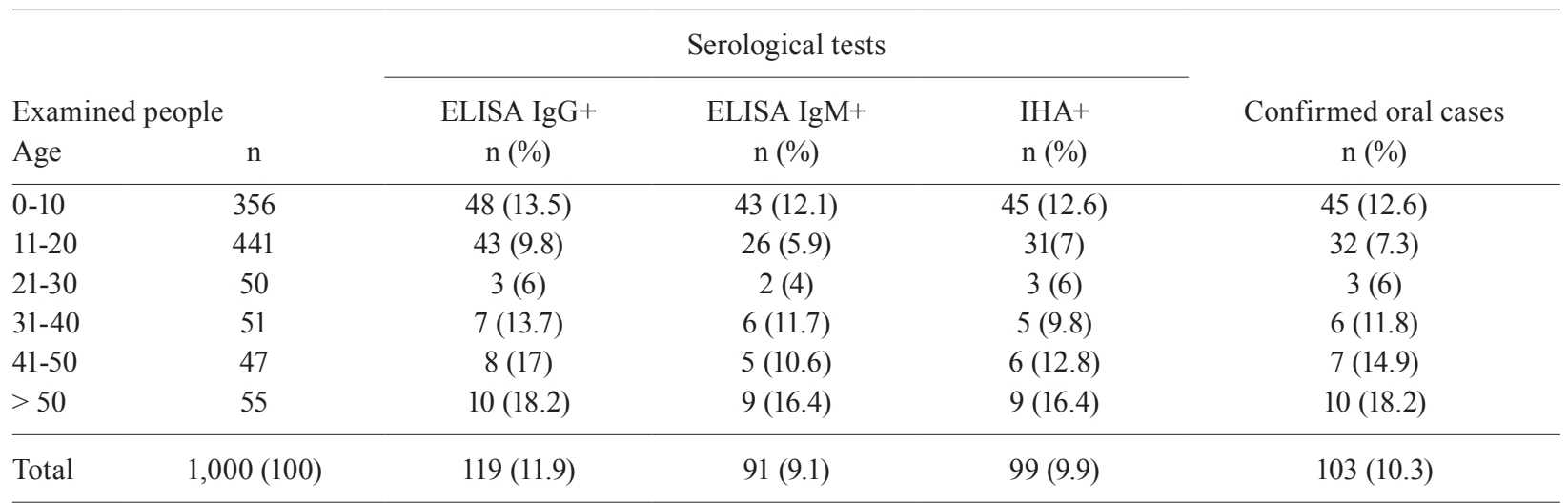

Ig: immunoglobulin; IHA: indirect haemagglutination. 
TABLE III

Immunodiagnosis patterns in 1,000 persons under risk in the acute oral outbreak of Chagas disease, Venezuela, 2007

\begin{tabular}{lccc}
\hline $\begin{array}{l}\text { Conventional } \\
\text { serology }\end{array}$ & Oral cases & Undefined & Uninfected \\
\hline IgG+ IgM+ IHA+ & 89 & 0 & 0 \\
IgG+ IgM+ IHA- & $1^{a}$ & 1 & 0 \\
IgG+ IgM- IHA+ & 10 & 0 & 0 \\
IgG+ IgM- IHA- & $3^{a}$ & 15 & 0 \\
IgG- IgM- IHA- & 0 & 0 & 881 \\
\hline Total & 103 & 16 & 881 \\
\hline
\end{tabular}

$a$ : confirmed by Western blot; IHA: indirect haemagglutination. Immunoglobulin (Ig)G and IgM detected by ELISA.

IgM antibodies, offering a rapid and inexpensive way to discriminate between infected and non-infected people.

WB is an additional type of immunological assay that was performed as a confirmatory test in the present study. This technique is specific, but it should not be used routinely in the diagnosis of $\mathrm{ChD}$ because it is time consuming and expensive and there is no general consensus regarding the specific diagnostic molecules.

The PCR technique applied in this study is a useful complementary tool, especially for post-treatment follow up. This method detected all but one of the parasitaemic patients. It is possible that the PCR result from patient 3 was a false negative because we did not perform internal controls that would have identified problems with the methodology, such as inhibition of PCR or loss of DNA during the extraction process. Comparing PCR results against a gold standard for the same sample provides an optimal comparison of sensitivity. In the present investigation, sensitivity was achieved using the combined serological techniques as a gold standard, but the denominator (number of positive results) was different in the group that underwent PCR testing compared with the group that underwent blood examination, culture and animal inoculation (Supplementary data). Nevertheless, the results are comparable because they are reported as percentages and were carried out in the same way as the procedures that performed in the field. The PCR analysis showed a sensitivity of $80.4 \%$, which was higher than the in vitro culture $(16.2 \%)$ and animal inoculation methods (11.6\%). During large acute outbreaks, samples for PCR analysis must be collected and stored at room temperature in preservation medium to be processed subsequently. PCR not only detects parasitaemic individuals, but also enables investigators to identify the parasite lineage and the intensity of the infection (via quantitative PCR) (Duffy et al. 2009).

The diagnosis of $\mathrm{ChD}$ was inconclusive in 16 individuals whose samples did not react in the second sero- logical confirmatory test (IHA or WB) (Zavala-Jaspe et al. 2005) (Table III). Nevertheless, due to the epidemiological nexus and the presence of some vague and nonspecific symptoms, the entire group was treated as probable cases and received anti-parasitic drugs (Alarcón de Noya et al. 2008); they were not treated as confirmed cases, due to the criteria established by the guidelines of the WHO (2002), which defines a case as any individual with at least two positive tests out of three serologic examinations. This group of inconclusive individuals is being subjected to a careful clinical and laboratory follow up investigation to exclude the possibility of infection.

There were a number of diagnostic lessons learned from the management of this outbreak. These lessons reinforce the widespread use of conventional serology methods for IgM detection and the use of all appropriate diagnostic techniques to detect the presence of the parasite. As pertains to this investigation and future investigations, all of the parasitological, immunological and molecular procedures used were essential for identifying the causal agent of the outbreak, T. cruzi, aiding in the diagnosis of acute $\mathrm{ChD}$. OChD can appear anywhere, causing outbreaks in groups ranging from small families to large communities. Clinicians, reference centres and $\mathrm{ChD}$ control programs should be aware of this new epidemiological situation and it is essential that public health personnel are prepared to perform a rapid integrated battery of diagnostic tests in case of an outbreak such as the one described herein. To our knowledge, the group investigated in this study was the largest group of patients with orally acquired $\mathrm{ChD}$ examined to date and, consequently, this study utilised the greatest number and most diverse set of diagnostic tests.

\section{ACKNOWLEDGEMENTS}

To the parents, guardians and authorities of the Andrés Bello Municipal School, to the Municipal Health Centre Salud Chacao, to the Dirección General Sectorial de Epidemiología del MPPS, to the professors from the Laboratorio de Amibiasis of the Escuela de Bioanálisis, to Lic. Ivonne Figuera, from IMT/UCV, for their help during the emergency, and to Dr Mariela Losada and Dr Peter Taylor, for their English revision of the manuscript.

\section{REFERENCES}

Alarcón de Noya B, Colmenares C, Ruiz-Guevara R, Díaz-Bello Z, Noya O 2010a. La transmisión oral de la enfermedad de Chagas. Rev Fac Med 33: 78-86.

Alarcón de Noya B, Díaz-Bello Z, Colmenares C, Ruiz-Guevara R, Mauriello L, Zavala-Jaspe R, Suárez JA, Abate T, Naranjo L, Paiva M, Rivas L, Castro J, Márques J, Mendoza I, Acquatella H, Torres J, Noya O 2010b. Large urban outbreak of orally-acquired acute Chagas disease, at a school in Caracas, Venezuela. J Infect Dis 201: 1308-1315.

Alarcón de Noya B, Díaz-Bello Z, Colmenares C, Ruiz-Guevara R, Noya O 2010c. Enfermedad de Chagas de transmisión oral: vinculación del caso índice con una microepidemia urbana en Venezuela. Bol Mal Salud Amb 50: 133-136.

Alarcón de Noya B, Díaz-Bello Z, Colmenares C, Zavala-Jaspe R, Mauriello L, Díaz MP, Soto M, Aponte M, Ruiz-Guevara R, Losada S, Noya-Alarcón O, Noya-González O 2009. Transmisión urbana de 
la enfermedad de Chagas en Caracas, Venezuela: aspectos epidemiológicos, clínicos y de laboratorio. Rev Biomed 20: 158-164.

Alarcón de Noya B, Martínez J 2009. Transmisión oral de la enfermedad de Chagas en Venezuela: un segundo brote escolar. Salus 13: 9-10.

Alarcón de Noya B, Torres J, Suárez JA, Márques J, Naranjo L, Noya O, Ruiz R 2008. Guía para el diagnóstico, manejo y tratamiento de la enfermedad de Chagas en fase aguda a nivel de los establecimientos de salud. Avances Cardiol 24: 250-267.

Añez N, Carrasco H, Parada H, Crisanti G, Rojas A, González N, Ramírez JL, Guevara P, Rivero C, Borges R, Scorza JV 1999. Acute Chagas disease in western Venezuela: a clinical, seroparasitologic and epidemiologic study. Am J Trop Med Hyg 60: 215-222.

Añez N, Crisante G, Parada H 2007. Nuevos casos agudos de enfermedad de Chagas en el occidente de Venezuela. Salus 11: 87-90.

Díaz-Bello Z, Zavala-Jaspe R, Díaz-Villalobos M, Mauriello L, Maekelt A, Alarcón de Noya B 2008. Diagnóstico confirmatorio de anticuerpos anti-Trypanosoma cruzi en donantes referidos por bancos de sangre en Venezuela. Invest Clin 49: 141-150.

Duffy T, Bisio M, Altcheh Burgos JM, Diez M, Levin MJ, Favaloro RR, Freilij H, Schijman AG 2009. Accurate real-time PCR strategy for monitoring bloodstream parasitic loads in Chagas disease patients. PLoS Negl Trop Dis 3: e419.

Feliciangeli M, Campbell-Lendrum D, Martínez C, González D, Coleman P, Davies C 2003. Chagas disease control in Venezuela: lessons for the Andean region and beyond. Trends Parasitol 19: 44-49.

González D, Medina M, Marrufo M, Rodríguez EM, Querales J 2005. Estandarización de pautas de diagnóstico de laboratorio de la enfermedad de Chagas en Venezuela. Comunidad y Salud 3: 21-27

Jacobs L, Lunde MN 1957. A hemagglutination test for toxoplasmosis. J Parasitol 43: 308-314.

Janeway CA, Travers P, Walport M, Shlomchik MJ 2001. Adaptative immunity to infection. In CA Janeway, P Travers, M Walport, MJ Shlomchik (eds.), Immunobiology, 5th ed., Churchill Livingstone, New York, p. 381-423.

Laemmli UK 1970. Cleavage of structural proteins during the assembly of the head of bacteriophage T4. Nature 227: 680-685.

Luquetti AO, Rassi A 2000. Diagnóstico laboratorial da infecção pelo Trypanosoma cruzi. In Z Brener, ZA Andrade, M Barral-Netto (eds.), Trypanosoma cruzi e doença de Chagas, 2nd ed., Guanabara Koogan, Rio de Janeiro, p. 344-378.

Maekelt GA 1960. Die komplement bin-dungs reaktion der Chagas krankeit ztsehr. Tropenmed Parasit 11:155-166.

Martín A, Alarcón de Noya B, Montero R, Rojas C, Garrido E, RuizGuevara R, Díaz-Bello Z 2009. Epidemia de Chagas agudo adquirido por vía oral en una escuela de Caracas: descripción del caso índice. Arch Venez Puer Ped 72: 97-100.

Morocoima A, Tineo E, Ferrer E, Herrera L, Núñez M 2008. Enfermedad de Chagas en el estado Anzoátegui, Venezuela: registro de un caso agudo y caracterización parasitológica y molecular del aislado. Bol Mal Salud Amb 48: 21-126.
Mourão OG, Mello OC 1975. Hemocultura para o diagnóstico parasitológico na fase crônica da doença de Chagas. Rev Soc Bras Med Trop 9: 183-188.

Noya O, Fermin Z, Alarcón de Noya B, Colmenares C, Hermoso T 1995. Humoral immune response of children with chronic schistosomiasis. Isotype recognition of adult worm antigens. Parasite Immunol 17: 319-328.

OPS/OMS - Organización Panamericana de la Salud/Organización Mundial de la Salud 2006. Informe de la consulta técnica en epidemiología, prevención y manejo de la transmisión de la enfermedad de Chagas como enfermedad transmitida por alimentos (ETA), Unidad Regional de Prevención y Control de Enfermedades Transmisibles, Grupo Técnico Especializado en Inocuidad de Alimentos, Rio de Janeiro, 103 pp.

ProMED 2012. Enfermedad de Chagas oral, brote en trabajadores de mercado de alimentos-Venezuela (CAR). Available from: promedmail.org.

Santalla Vargas J, Oporto Carrasco P, Espinoza E, Ríos T, Brutus L 2011. Primer brote reportado de la enfermedad de Chagas en la Amazonía Boliviana: reporte de 14 casos agudos por transmisión oral de Trypanosoma cruzi en Guayaramerín, Beni-Bolivia. BIOFARBO 19: 52-58.

Schijman AG, Altcheh J, Burgos JM, Biancardi M, Bisio M, Levin MJ, Freilij H 2003. Aetiological treatment of congenital Chagas disease diagnosed and monitored by the polymerase chain reaction. J Antimicrob Chemother 52: 441-449.

Shikanai-Yasuda MA, Barbosa Carvalho NB 2012. Oral transmission of Chagas disease. Clin Infect Dis 54: 845-852.

Strout RG 1962. A method for concentrating hemoflagellates. J Parasitol 48: 100 .

Sturm N, Degrave W, Morel C, Simpson L 1989. Sensitive detection and schizodeme classification of $T$. cruzi cells by amplification of kinetoplastid minicircle DNA sequences: use in diagnosis of Chagas disease. Mol Biochem Parasitol 33: 205-214.

Valente SAS, Valente VC, Pinto AYN, César MJB, Santos MP, Miranda COS, Cuervo P, Fernándes O 2008. Analysis on an acute Chagas disease outbreak in the Brazilian Amazon: human cases, triatomines, reservoir, mammals and parasites. Trans $R$ Soc Trop Med Hyg 103: 291-297.

Voller A, Bidwell DE, Bartlett A, Fleck DG, Perkins M, Oladehin B 1976. A microplate enzyme-immunoassay for Toxoplasma antibody. J Clin Pathol 29: 150-153.

WHO - World Health Organization 2002. Control of Chagas disease. Second report of the WHO Expert Committee. WHO Tech Rep Ser 905: 109 .

WHO - World Health Organization 2007. Consultation on international biological reference preparations for chagas diagnostic tests, WHO, Geneva, $25 \mathrm{pp}$.

Zavala-Jaspe R, Díaz-Bello Z, Alarcón de Noya B 2005. Evaluación de un antígeno de epimastigotes de Trypanosoma cruzi cepa PM (1958) para el diagnóstico de la Enfermedad de Chagas en Venezuela. Parasitol Latinoam 60: 194. 


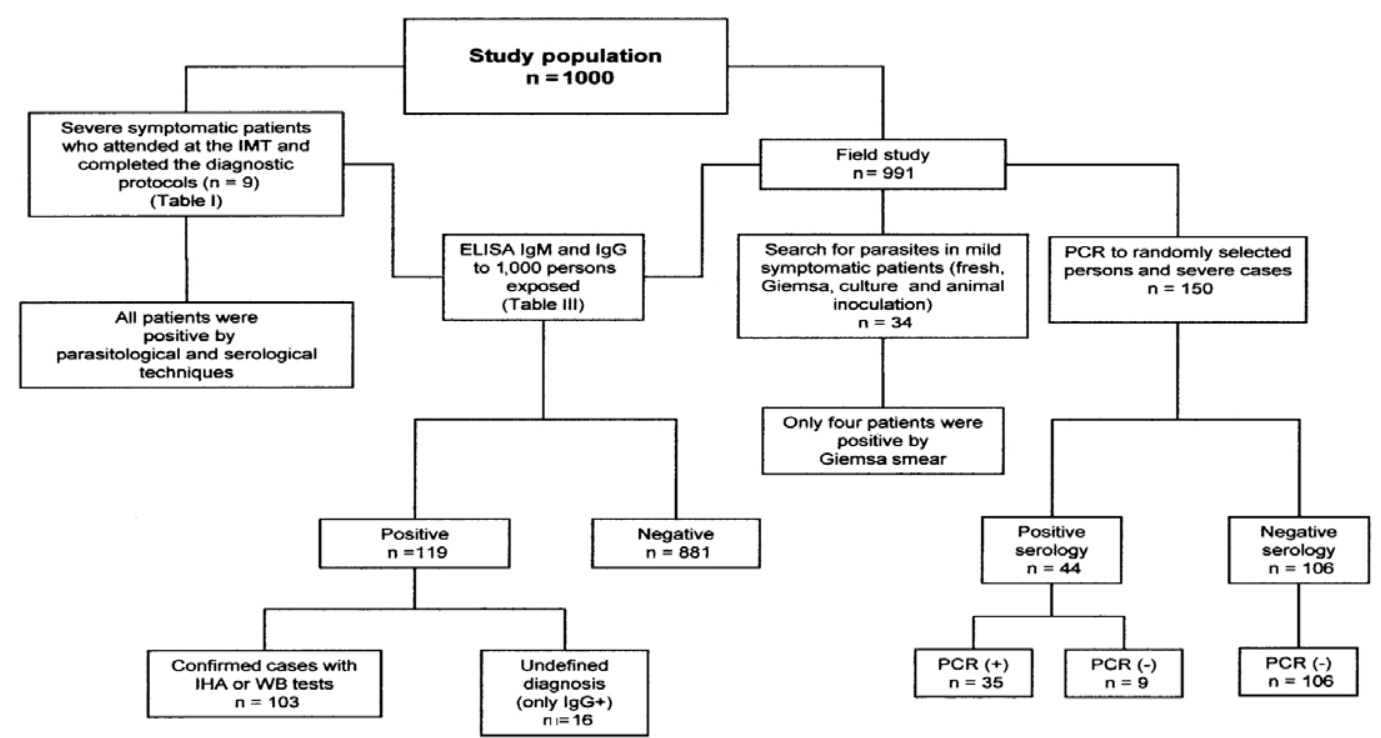

Study profile and outcomes of laboratory diagnosis from the outbreak of acute Chagas disease, Caracas, Venezuela, 2007. IHA: indirect haemagglutination; IMT: Tropical Medicine Institute; PCR: polymerase chain reaction; WB: western blot. 